\title{
An Efficient Method for Plant Regeneration from Calli of Swertia mussotii, an Endangered Medicinal Herb
}

\author{
Tao He*, Jing Xu, Lina Yang, Haitao Wang
}

Department of Biosciences, Qinghai University, Xining, China.

Email: *hetaoxn@yahoo.cn

Received May 22 ${ }^{\text {nd }}, 2012$; revised June $19^{\text {th }}, 2012$; accepted June $27^{\text {th }}, 2012$

\begin{abstract}
Swertia mussotii Franch is an endangered medicinal plant in the Qinghai-Tibet Plateau. Its regeneration from callus culture is very difficult. In this study, an efficient method for plant regeneration was developed from its calli. The calli derived from young stem explants of S. mussotii were cultured at two types of temperature treatments to test their efficiency of shoot regeneration. When the calli were cultured at variable temperature $\left(\mathrm{VT}, 20^{\circ} \mathrm{C}\right.$ during the day and $10^{\circ} \mathrm{C}$ at night) treatment, the adventitious shoots were formed at each combination tested. However, that did not occur when the calli were cultured at constant temperature $\left(\mathrm{CT}, 25^{\circ} \mathrm{C}\right)$ treatment. The best response $(53.7 \%)$ of plantlet regeneration was obtained on Murashige and Skoog (MS) medium containing $3 \mathrm{mg} \cdot \mathrm{l}^{-1}$ 6-benzylaminopurine with $0.5 \mathrm{mg} \cdot \mathrm{l}^{-1} \alpha$ naphthaleneacetic acid in the VT treatment. The regenerated plantlets were rooted on half-strength MS medium without growth regulators. They flowered in the following subculture. The results indicate that the treatment of day-night temperature difference is a critical factor to callus differentiation in S. mussotii. This protocol can be used for conservation as well as mass propagation of this medicinal plant.
\end{abstract}

Keywords: Swertia mussotii; Medicinal Plant; Callus Induction; Plant Regeneration; Day-Night Temperature Difference

\section{Introduction}

Swertia mussotii Franch, commonly known as "Zang Yin Chen" in China, is an annual herb in the family Gentianaceae. It grows mainly in the alpine and subalpine belts in the Qinghai-Tibet Plateau at altitudes of 3200 to $4000 \mathrm{~m}$ [1]. S. mussotii are collected and used mostly for their medicinal effects. Its major active compounds have been shown to be swertiamarin, mangiferin and gentiopicroside, which possess unique medicinal properties against rheumatism, osteoarthritis, hepatitis, gastritis and cholecystitis [2]. A medicine has been produced from this plant and sold as capsules for the treatment of these diseases [1]. Demand for S. mussotii in the pharmaceutical industry is met from the wild. As a result of over harvesting and lack of organized cultivation, S. mussotii is now on the list of rare and threatened species in China. $S$. mussotii regenerates through seeds. However, its germination is low and progresses slowly under natural conditions [3]. Therefore, it is imperative to develop appropriate tissue culture techniques for this species.

Plant tissue culture provides a viable alternative for

"Corresponding author. managing these valuable resources in a sustainable manner. Plant propagation via in vitro micropropagation is one of the easiest and fastest methods of producing numerous plantlets in a limited time period [4]. Most importantly, micropropagation provides an efficient protocols for conservation of plant biodiversity and multiplication of the endangered species. Recently, in vitro propagation procedures have been adopted for large-scale propagation of a number of medicinal plants in the family Gentianaceae [5-10]. Despite being a valuable medicinal plant, very little work has been done on tissue culture of S. mussotii. Xiang et al. [11] described callus induction from immature embryos, hypocotyl and leaf segments of this species, but they failed to obtain regenerated shoots from these calli. A similar result without plantlet regeneration from calli of $S$. mussotii was reported by Liu and Chen [12]. Previous researches have indicated that shoot regeneration from calli of S. mussotii was difficult $[11,12]$. In this study, we established an efficient regeneration protocol using young stem derived calli of $S$. mussotii by treatment of day-night temperature difference. This in vitro propagation protocol should be useful for conservation as well as mass propagation of this endangered species. 


\section{Materials and Methods}

Mature seeds of Swertia mussotii Franch were collected during the months of September and October from Yushu county of Qinghai province in China. They were surface sterilized with $70 \%(v / v)$ ethanol for $45 \mathrm{~s}$, then with $0.1 \%$ mercuric chloride $\left(\mathrm{HgCl}_{2} ; w / v\right)$ for $12 \mathrm{~min}$, and rinsed five times with sterile distilled water. The seeds were germinated on half-strength Murashige and Skoog (MS) [13] medium supplemented with 3\% (w/v) sucrose and $0.8 \%(w / v)$ agar without growth regulators. Young stems excised from 2-month-old seedlings were used for the explants.

For callus induction, young stem segments were cultured on MS medium supplemented with $0.5-4 \mathrm{mg} \cdot \mathrm{l}^{-1}$ 2,4-dichlorophenoxyacetic acid (2,4-D) alone or in combination with 6-benzylaminopurine (BA) $\left(0.5,1 \mathrm{mg} \cdot l^{-1}\right)$, $3 \%(\mathrm{w} / \mathrm{v})$ sucrose and $0.65 \mathrm{~g} \cdot \mathrm{l}^{-1}$ agar. The cultures were maintained at $25^{\circ} \mathrm{C} \pm 2^{\circ} \mathrm{C}$ with a $16 \mathrm{~h}$ photoperiod. A light intensity of $30 \mu \mathrm{mol} \cdot \mathrm{m}^{-2} \cdot \mathrm{s}^{-1}$ was provided by coolwhite fluorescent lamps. Explants forming calli were scored after 6 weeks of culture and the percentage response was calculated. Primary calli were subcultured on MS medium containing different concentrations of 2,4-D $\left(0.5-2 \mathrm{mg} \cdot \mathrm{l}^{-1}\right)$ for proliferation. Calli were subcultured at 3 weeks intervals.

For plantlet regeneration, the calli were transferred to MS medium supplemented with $0.5-4 \mathrm{mg} \cdot \mathrm{l}^{-1} \mathrm{BA}$ alone or in combination with $\alpha$-naphthaleneacetic acid (NAA) $\left(0.5,1 \mathrm{mg} \cdot 1^{-1}\right)$. The calli were cultured at two types of temperature treatments to test their efficiency of shoot regeneration. One type was constant temperature (CT, $25^{\circ} \mathrm{C}$ ) treatment; the other was variable temperature (VT, $20^{\circ} \mathrm{C}$ during the day and $10^{\circ} \mathrm{C}$ at night) treatment. The regeneration frequency was scored after 6 weeks of culture. The regenerated plantlets $(1-2 \mathrm{~cm}$ in height) were initially maintained on half-strength MS medium without growth regulators for rooting.

Each treatment consisted of 20 replicates and each experiment was repeated at least three times. Data were analyzed statistically using Duncan's multiple range test [14].

\section{Results and Discussion}

Difficulty in seed germination of S. mussotii was reported by Yang and Liu [3]. In this study, approximately $17 \%$ of the seeds germinated within 4 weeks of inoculation on the growth regulator-free MS medium. The seeds developed into plantlets $(3-4 \mathrm{~cm})$ consisting of four to five leaves within 2 months of germination. Young stem explants from these seedlings were subsequently used for all experiments.

Swelling and expansion in the explants were observed 4 - 5 days after culture initiation. Callus formation started after 10 days from the cut ends of the stem segments. After 6 weeks of culture, two types of calli were recognized. One type consisted of soft, white calli; the other consisted of nodular, yellow calli (Figure 1(A)). Table 1 shows the effects of different concentrations of 2,4-D and $\mathrm{BA}$ on callus formation. The induction frequency of callus ranged from $58.0 \%$ to $90.1 \%$ depending on the $2,4-\mathrm{D}$ concentrations. With an increase in the 2,4-D concentrations, the induction frequency was increased, but it declined at the highest concentration $\left(4 \mathrm{mg} \cdot \mathrm{l}^{-1}\right)$. In general, auxins play a critical role in the induction of callus. However, high concentrations of auxin restrain their further development. Choi et al. [15] assumed that higher concentrations of 2,4-D might result in a greater possibility of somatic mutation. The use of cytokinins in combination with auxins has been reported to promote callus induction [16]. Similarly, we observed that the addition of $0.5 \mathrm{mg} \cdot 1^{-1}$ BA to the medium with 2,4-D $\left(1-3 \mathrm{mg} \cdot 1^{-1}\right)$ resulted in an increase in callus. Among the tests, 3 $\mathrm{mg} \cdot \mathrm{l}^{-1} 2,4-\mathrm{D}$ and $0.5 \mathrm{mg} \cdot \mathrm{l}^{-1} \mathrm{BA}$ were the most effective, with the highest frequency $(90.1 \%)$ of forming callus (Table 1). In this study, either 2,4-D or a combination of 2,4-D with BA was effective in inducing callus.

The two types of calli were transferred to the developing medium, MS medium containing different concentrations of 2,4-D $\left(0.5-2 \mathrm{mg} \cdot \mathrm{l}^{-1}\right)$ for subculture. On this medium, the soft, white calli grew slowly, most of them turned brown and eventually died as a result of a watery substance covering the calli. The nodular, yellow calli exhibited rapid growth, most of them became more compact in structure (Figure 1(B)). Therefore, the yellow nodular calli were used in further tissue culture steps. Of the concentration tested, $0.5 \mathrm{mg} \cdot \mathrm{l}^{-1} 2,4-\mathrm{D}$ may be the optimal concentration for subculture.

After 6 weeks of subculture, the calli were transferred to the regeneration medium. They were cultured in the CT and VT treatments, respectively. As shown in Table $\mathbf{2}$, the regeneration potential of the calli was greatly influenced by different treatments and growth regulators added to the medium. The capacity of plant regeneration from the calli cultured in the VT treatment was signifycantly higher than that cultured in the CT treatment (Table 2). In the VT treatment, adventitious shoot formation was observed at each combination tested (Table 2, Figures 1(C)-(E)). However, no shoot formation was observed in the CT treatment (Table 2). In the CT treatment, only adventitious roots were observed on the surface of calli (Figure 1(F)). Similar results were reported previously in other Swertia plants, such as S. franchetiana [17] and S. davidii [18].

$S$. mussotii is one of alpine plant species, which distributes mainly in the Qinghai-Tibet Plateau. The unique climate of this region is characterized by large temperature difference between day and night. By the long-term 

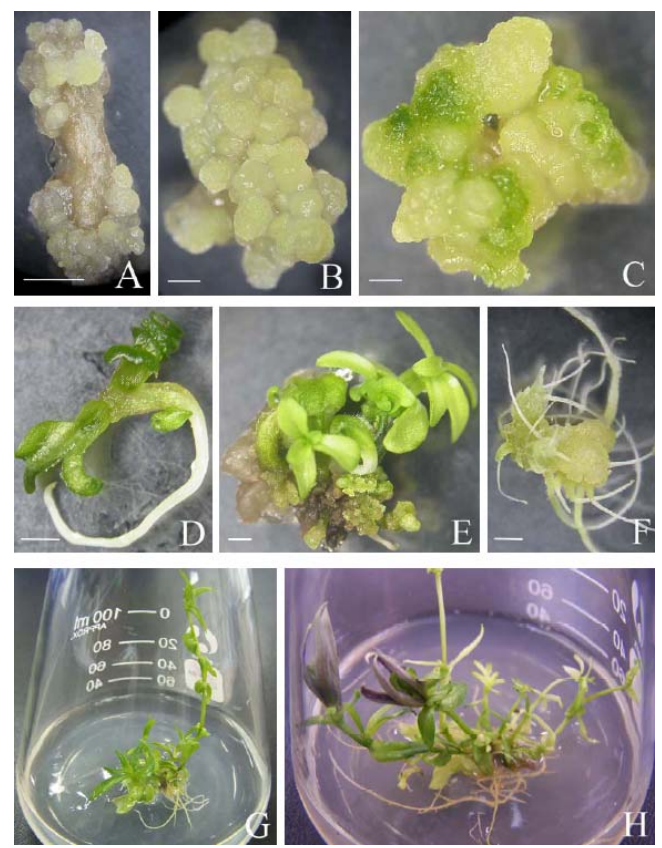

Figure 1. Callus induction and plant regeneration in Swertia mussotii. (A) Primary calli from young stem explant; (B) The calli subcultured on MS medium containing $0.5 \mathrm{mg} \cdot \mathrm{l}^{-1}$ 2,4-D; (C) Green shoot bud formation on the surface of calli; (D) Well-developed shoots with root; (E) Adventitious shoot formation on the surface of calli; (F) Adventitious root formation on the surface of calli; (G) Rooting of shoot on half-strength MS medium without growth regulators; $(\mathrm{H})$ The regenerated plantlets flowered in vitro. Bars: $1 \mathrm{~mm}$.

Table 1. Effect of 2,4-D and BA on callus induction of young stem explants of Swertia mussotii.

\begin{tabular}{ccc}
\hline $2,4-\mathrm{D}\left(\mathrm{mg} \cdot \mathrm{l}^{-1}\right)$ & BA $\left(\mathrm{mg} \cdot \mathrm{l}^{-1}\right)$ & $\begin{array}{c}\text { Frequency of callus } \\
\text { induction }(\%)\end{array}$ \\
\hline 0.5 & 0 & $58.3 \pm 3.4^{\mathrm{c}}$ \\
1 & 0 & $66.7 \pm 2.6^{\mathrm{bc}}$ \\
1 & 0.5 & $72.7 \pm 1.8^{\mathrm{b}}$ \\
1 & 1 & $66.5 \pm 1.7^{\mathrm{bc}}$ \\
2 & 0 & $71.6 \pm 3.7^{\mathrm{b}}$ \\
2 & 0.5 & $80.7 \pm 2.1^{\mathrm{ab}}$ \\
2 & 1 & $73.4 \pm 2.1^{\mathrm{b}}$ \\
3 & 0 & $83.2 \pm 3.2^{\mathrm{a}}$ \\
3 & 0.5 & $90.1 \pm 4.7^{\mathrm{a}}$ \\
4 & 1 & $58.0 \pm 1.3^{\mathrm{c}}$ \\
\hline
\end{tabular}

Evaluation was carried out 6 weeks after culture initiation. Values were means \pm S.E. (standard error). Frequency of callus induction was calculated as (number of calli/number of explants cultured) $\times 100 .{ }^{a-c}$ Values followed by different letters in a column are significantly different at $P<0.05$ according to Duncan's multiple range test.
Table 2. Effect of different treatments and combinations of growth regulators on shoot regeneration from calli of Swertia mussotii.

\begin{tabular}{cccc}
\hline \multirow{2}{*}{ BA $\left(\mathrm{mg} \cdot 1^{-1}\right)$} & NAA $\left(\mathrm{mg} \cdot 1^{-1}\right)$ & \multicolumn{2}{c}{ Regeneration capacity of calli (\%) } \\
\cline { 3 - 4 } & & CT treatment & VT treatment \\
\hline 0.5 & 0 & 0.0 & $12.6 \pm 1.5^{\mathrm{e}}$ \\
1 & 0 & 0.0 & $23.9 \pm 2.7^{\mathrm{d}}$ \\
1 & 0.5 & 0.0 & $29.4 \pm 2.9^{\mathrm{d}}$ \\
1 & 1 & 0.0 & $18.8 \pm 1.6^{\mathrm{e}}$ \\
2 & 0 & 0.0 & $31.3 \pm 4.6^{\mathrm{cd}}$ \\
2 & 0.5 & 0.0 & $45.3 \pm 2.1^{\mathrm{ab}}$ \\
2 & 1 & 0.0 & $50.6 \pm 2.9^{\mathrm{ab}}$ \\
3 & 0 & 0.0 & $41.7 \pm 1.7^{\mathrm{bc}}$ \\
3 & 0.5 & 0.0 & $53.7 \pm 3.2^{\mathrm{a}}$ \\
3 & 1 & 0.0 & $32.4 \pm 1.8^{\mathrm{c}}$ \\
4 & 0 & 0.0 & $20.3 \pm 2.4^{\mathrm{de}}$ \\
\hline
\end{tabular}

Evaluation was carried out 6 weeks after transfer of calli to regeneration medium. Values were means \pm S.E. (standard error). Regeneration capacity of calli was calculated as (number of calli with green shoots/number of calli plated on regeneration medium) $\times 100$. ${ }^{\mathrm{a}-\mathrm{e}}$ Values followed by different letters in a column are significantly different at $P<0.05$ according to Duncan's multiple range test.

of natural selection, S. mussotii possesses special acclimation structures and mechanisms that allow them to survive in this environment. It was useful for plant tissue culture to consider the environmental conditions in the original regions of the plant species [10]. In this study, cultures were maintained at $20^{\circ} \mathrm{C}$ during the day and $10^{\circ} \mathrm{C}$ at night, which approached the environment temperature of $S$. mussotii growth. Similar culture condition was reported previously in Saussurea laniceps, an alpine plant growing in the Qinghai-Tibet Plateau [19]. Unfortunately, the frequencies of shoot regeneration were relatively low in the VT treatment (Table 2). This was probably due to the fact that a few calli produced directly adventitious roots instead of shoots in this treatment. In the VT treatment, the highest frequency $(53.7 \%)$ of plantlet regeneration was obtained on MS medium containing $3 \mathrm{mg} \cdot \mathrm{l}^{-1}$ BA with $0.5 \mathrm{mg} \cdot \mathrm{l}^{-1}$ NAA (Table 2). Although previous researches reported the callus formation from $S$. mussotii, shoot regeneration was not obtained from these calli $[11,12]$. In this study, however, we obtained successfully adventitious shoots from the calli by treatment of day-night temperature difference. Our results indicated that the treatment of day-night temperature difference was a critical factor to callus differentiation in S. mussotii. However, the functional mechanism of this treatment in promoting this plant regeneration is not clear. We assumed that the calli of $S$. mussotii might 
experience changes during the treatment on a molecular and/or cellular level, resulting in the enhancement of regeneration efficiency. Further experiments to determine the effects of temperature in the original regions of S. mussotii on its in vitro culture are in progress.

When multiple shoots grown on regeneration medium were divided and transferred to rooting medium, thick white roots developed in about 4 weeks (Figure 1(G)). Interestingly, the regenerated plantlets flowered in vitro after 3 months of subculture (Figure 1(H)). In vitro flowering was also reported previously in other plants [20,21]. In report of Makunga and Staden [20], in vitro flowering in Salvia Africana-lutea became apparent seasonally throughout the year. In Psygmorchis pusilla, a positive relationship was observed between long days and floral spike formation [21]. In this study, we assumed that in vitro flowering in S. mussotii might be related to day-night temperature difference treatment. Because in vitro flowering was not observed when the regenerated plantlets were subcultured at constant $25^{\circ} \mathrm{C}$. However, no fertile seeds were obtained from the regenerants flowered in vitro.

In conclusion, an efficient regeneration protocol via indirect adventitious shoot formation was established from young stem explants of $S$. mussotii, an endangered medicinal plant. This in vitro technique should be a very useful tool for the conservation and propagation of $S$. mussotii.

\section{Acknowledgements}

This work was financially supported by the National Natural Science Foundation of China (30960161) and State Key Laboratory Breeding Base for Innovation and Utilization of Plateau Crop Germplasm (2011-02).

\section{REFERENCES}

[1] Y. C. Yang, "Tibetan Medicines," Qinghai People Press, Xining, 1991, p. 142.

[2] G. Brahmachari, S. Mondal, A. Gangopadhyay, D. Gorai, B. Mukhopadhyay, S. Saha and A. K. Brahmachari, "Swertia (Gentianaceae): Chemical and Pharmacological Aspects," Chemistry \& Biodiversity, Vol. 1, No. 11, 2004, pp. 1627-1651. doi:10.1002/cbdv.200490123

[3] H. L. Yang and J. Q. Liu, "Seed Germination of Swertia mussotii, an Important Application in Tibetan Folk Medicine," Acta Botanica Yunnanica, Vol. 27, 2005, pp. 295-300.

[4] S. S. Bhojwani and M. K. Razdan, "Plant Tissue Culture: Theory and Practice," Elsevier Science, Amsterdam, 1996, pp. 1-767.

[5] A. Mikula, A. Fiuk and J. J. Rybczynski, "Induction, Maintenance and Preservation of Embryogenic Competence of Gentiana cruciata L. Cultures," Acta Biologica Cracoviensia, Vol. 47, 2005, pp. 227-236.
[6] P. Joshi and V. Dhawan, "Axillary Multiplication of Swertia chirayita (Roxb. Ex Fleming) H. Karst., a Critically Endangered Medicinal Herb of Temperate Himalayas," In Vitro Cellular \& Developmental Biology-Plant, Vol. 43, No. 6, 2007, pp. 631-638. doi:10.1007/s11627-007-9065-2

[7] R. K. Chaudhuri, A. Pal and T. B. Jha, "Conservation of Swertia chirata through Direct Shoot Multiplication from Leaf Explants," Plant Biotechnology Reports, Vol. 2, No. 3, 2008, pp. 213-218. doi:10.1007/s11816-008-0064-5

[8] A. Fiuk and J. J. Rybczynski, "Genotype and Plant Growth Regulator-Dependent Response of Somatic Embryogenesis from Gentiana spp. Leaf Explants," In Vitro Cellular \& Developmental Biology-Plant, Vol. 44, No. 2, 2008, pp. 90-99. doi:10.1007/s11627-008-9124-3

[9] H. Doi, R. Takahashi, T. Hikage and Y. Takahata, "Embryogenesis and Doubled Haploid Production from Anther Culture in Gentian (Gentiana triflora)," Plant Cell, Tissue and Organ Culture, Vol. 102, No. 1, 2010, pp. 2733. doi:10.1007/s11240-010-9700-1

[10] T. He, L. N. Yang and Z. G. Zhao, "Embryogenesis of Gentiana straminea and Assessment of Genetic Stability of Regenerated Plants Using inter Simple Sequence Repeat (ISSR) Marker," African Journal of Biotechnology, Vol. 10, No. 39, 2011, pp. 7604-7610.

[11] F. N. Xiang, J. M. Li, J. X. Ma and X. M. Wu, "Tissue Culture of calli of Swertia musstii Franch," Chinese Traditional Herbal Drugs, Vol. 27, 1996, pp. 492-495.

[12] J. C. Liu and X. Y. Chen, "Tissue Culture and Rapid Propagation of Swertia mussotii," Plant Physiology Communications, Vol. 39, 2003, p. 237.

[13] T. Murashige and F. Skoog, "A Revised Medium for Rapid Growth and Bioassays with Tobacco Tissues Cultures," Physiologia Plantarum, Vol. 15, No. 3, 1962, pp. 473-497. doi:10.1111/j.1399-3054.1962.tb08052.x

[14] H. L. Harter, "Critical Values for Duncan's Multiple Range Test," Biometrics, Vol. 16, No. 4, 1960, pp. 671685. doi: $10.2307 / 2527770$

[15] H. Choi, P. G. Lemaux and M. Cho, "Selection and Osmotic Treatment Exacerbate Cytological Aberrations in Transformed Barley (Hordeum vulgare L.)," Journal of Plant Physiology, Vol. 158, No. 7, 2001, pp. 935-943. doi:10.1078/0176-1617-00389

[16] M. Capuana, G. Petrini, A. D. Marco and R. Giannini, "Plant Regeneration of Common Ash (Fraxinus excelsior L.) by Somatic Embryogenesis," In Vitro Cellular \& Developmental Biology-Plant, Vol. 43, No. 2, 2007, pp. 101-110. doi:10.1007/s11627-007-9030-0

[17] F. N. Xiang, M. Q. Xing, G. M. Xia, F. Z. Hu and Y. Li, "Tissue Culture and Antihepatis Constituent in Calli of Swertia franchetiana $\mathrm{H}$. Smith," Bulletin of Botanical Research, Vol. 19, 1999, pp. 172-179.

[18] H. Y. Huang and Y. G. Chen, "Tissue Culture of Medical Plant Swertia davidii Franch," Guihaia, Vol. 22, 2002, pp. 433-436.

[19] Y. Z. Chen and F. L. Li, "Micropropagation and Callus Culture of Saussurea laniceps, an Alpine Medicinal Plant," Forestry Studies in China, Vol. 7, 2005, pp. 16-19. 
doi:10.1007/s11632-005-0051-7

[20] N. P. Makunga and J. V. Staden, "An Efficient System for the Production of Clonal Plantlets of the Medicinally Important Aromatic Plant: Salvia africana-lutea L.," Plant Cell, Tissue and Organ Culture, Vol. 92, No. 1, 2008, pp. 63-72. doi:10.1007/s11240-007-9305-5
[21] A. P. A. Vaz, R. C. L. Figueiredo-Ribeiro and G. B. Kerbauy, "Photoperiod and Temperature Effects on in Vitro Growth and Flowering of $P$. pusilla, an Epiphytic Orchid," Plant Physiology and Biochemistry, Vol. 42, No. 5, 2004, pp. 411-415. doi:10.1016/j.plaphy.2004.03.008

\section{Abbreviations}

MS: Murashige and Skoog medium

2,4-D: 2,4-Dichlorophenoxyacetic acid

BA: 6-Benzylaminopurine

NAA: $\alpha$-Naphthaleneacetic acid

VT: Variable temperature treatment

CT: Constant temperature treatment 